\title{
Mechanochemical Synthesis of Cocrystals of Betulin with Adipic Acid
}

\author{
Svetlana A. Myza, Mikhail A. Mikhailenkoa, \\ Anastasiya V. Mikhailovskaya ${ }^{\mathrm{a}, \mathrm{b}}$, Anatoly A. Politov ${ }^{\mathrm{a}, \mathrm{b}}$, \\ Svetlana A. Kuznetsova ${ }^{c}$ and Tatyana P. Shakhtshneider*a \\ ${ }^{a}$ Institute of Solid State Chemistry and Mechanochemistry SB RAS \\ Novosibirsk, Russian Federation \\ ${ }^{b}$ Novosibirsk State University \\ Novosibirsk, Russian Federation \\ 'Institute of Chemistry and Chemical Technology SB RAS \\ FRC "Krasnoyarsk Science Center SB RAS" \\ Krasnoyarsk, Russian Federation
}

Abstract. The cocrystal of betulin with adipic acid was prepared using a liquid-assisted grinding method. The formation of cocrystal was confirmed by powder X-ray diffraction and IR spectroscopy methods. In order to choose a liquid for preparing cocrystal, solvents of different polarity were compared. It was shown that cocrystal of betulin with adipic acid was formed if solvents were used during mechanical treatment, in which the increased solubility of adipic acid was observed.

Keywords: mechanochemical synthesis, betulin, cocrystals, adipic acid.

Citation: Myz S.A., Mikhailenko M.A., Mikhailovskaya A.V., Politov A.A., Kuznetsova S.A., Shakhtshneider T.P. Mechanochemical synthesis of cocrystals of betulin with adipic acid, J. Sib. Fed. Univ. Chem., 2020, 13(4), 511-524. DOI: $10.17516 / 1998-2836-0202$

(C) Siberian Federal University. All rights reserved

This work is licensed under a Creative Commons Attribution-NonCommercial 4.0 International License (CC BY-NC 4.0).

* Corresponding author E-mail address: shah@solid.nsc.ru 


\title{
Механохимический синтез смешанных кристаллов бетулина с адипиновой кислотой
}

\author{
С.А. Мызь ${ }^{a}$, М.А. Михайленко ${ }^{a}$, А.В. Михайловская ${ }^{a, \tilde{\sigma}}$, \\ А.А. Политов ${ }^{\text {a, }}$, С.А. Кузнецова ${ }^{\mathrm{B}}$, Т.П. Шахтшнейдер ${ }^{\mathrm{a}}$ \\ ${ }^{a}$ Институт химии твердого тела и механохимии СО РАН \\ Российская Федерация, Новосибирск \\ ${ }^{6}$ Новосибирский государственныий университет \\ Российская Федерация, Новосибирск \\ ${ }^{6}$ Институт химии и химической технологии \\ ФИЦ «Красноярский научный центр СО РАН» \\ Российская Федерачия, Красноярск
}

Аннотация. Смешанные кристаллы бетулина с адипиновой кислотой получены механохимической активацией при добавлении небольших количеств органических растворителей. Образование смешанных кристаллов подтверждено методами рентгенофазового анализа и ИК-спектроскопии. С целью выбора жидкости для приготовления смешанных кристаллов проведено сравнение растворителей различной полярности. Показано, что смешанные кристаллы бетулина с адипиновой кислотой образуются, если при механической обработке используются растворители, хорошо растворяющие адипиновую кислоту.

Ключевые слова: механохимический синтез, бетулин, смешанные кристаллы, адипиновая кислота.

Цитирование: Мызь, С.А. Механохимический синтез смешанных кристаллов бетулина с адипиновой кислотой $/$ С.А. Мызь, М.А. Михайленко, А.В. Михайловская, А.А. Политов, С.А. Кузнецова, Т.П. Шахтшнейдер // Журн. Сиб. федер. ун-та. Химия, 2020. 13(4). С. 511-524. DOI: 10.17516/1998-2836-0202

В последнее время бетулин и его производные вызывают все больший интерес благодаря широкому спектру их биологической и фармакологической активности, включая противовирусную, антибактериальную, противовоспалительную, противоопухолевую $[1,2]$. Однако бетулин, как и многие его производные, обладает плохой растворимостью в воде, что снижает его биодоступность. Разнообразные методы были использованы для улучшения растворимости и/или скорости растворения бетулина и его производных, такие как приготовление твердых дисперсий с водорастворимыми полимерами [3], липосомами [4], производными циклодекстрина [5], встраивание в наносистемы [6] и др. Недостатком этих методов является низкая стабильность таких систем, поскольку лекарственное вещество, как правило, находится в аморфном состоянии и связано с носителем слабыми водородными или вандерваальсовыми связями. Поэтому необходимо искать новые подходы для увеличения скорости растворения и растворимости бетулина.

Для улучшения растворимости активных фармацевтических ингредиентов (АФИ) возможно также получение их кристаллических форм. Это могут быть полиморфные модификации, 
солевые формы, сольваты и гидраты, а также смешанные кристаллы, обладающие повышенной скоростью растворения [7]. Получение смешанных кристаллов, т.е. многокомпонентных кристаллических систем, содержащих в своей структуре АФИ и нетоксичные молекулы-партнеры, связанные с лекарственными молекулами, как правило, водородными связями, привлекло интерес в фармации в качестве стратегии для изменения физико-химических свойств, в том числе скорости растворения и растворимости, лекарственных веществ $[8,9]$.

Адипиновая кислота широко используется в фармации для получения смешанных кристаллов. На рис. 1 представлены структурные формулы бетулина и адипиновой кислоты. Бетулин имеет вторичные и первичные гидроксильные группы, которые, можно ожидать, способны вступать в водородные связи с функциональными группами дикарбоновой кислоты с образованием смешанного кристалла.

Синтез органических соединений в твердой фазе, в том числе и смешанных кристаллов, затруднен вследствие диффузионных ограничений для органических молекул. Синтез проходит успешно, если реакция идет через флюидную фазу, в которой один или оба реагента обладают достаточной подвижностью, и смешивание компонентов может происходить на молекулярном уровне. Поэтому для приготовления смешанных кристаллов применяют методы кристаллизации из раствора или из расплава. В первом случае универсальному использованию метода мешает низкая растворимость препаратов в малотоксичных растворителях, во втором случае многие биологически активные вещества при температуре плавления разлагаются или окисляются, что приводит к загрязнению препаратов посторонними примесями. Вышеупомянутых недостатков часто удается избежать, если использовать механохимические методы синтеза, при которых в результате механических воздействий происходит массоперенос и смешение на субмолекулярном уровне. Возникающее при механических воздействиях короткое $\left(10^{-2}-10^{-3} \mathrm{c}\right)$ импульсное нагревание приводит к молекулярному перемешиванию. Однако за короткие времена нагрева, как правило, не успевают произойти химические превращения веществ, которые, как показывают эксперимент и расчеты, требуют значительно большего времени. В последнее время получил развитие механохимический синтез веществ с добавлением небольшого количества растворителя [10-12]. Такой метод в англоязычной литературе получил название «liquid-assisted grinding», или LAG-синтез. Количество растворителя по отношению к исходным компонентам берут от 1 \% и менее, что

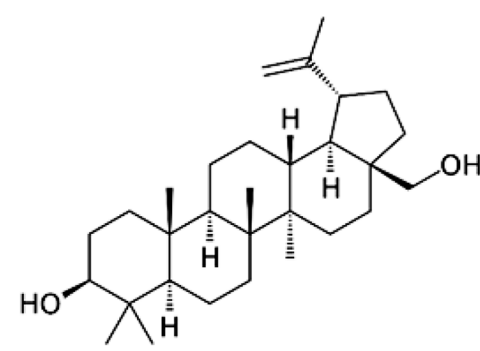

a<smiles>O=C(O)CCCCC(=O)O</smiles>

b

Рис. 1. Молекулярные структуры бетулина (a) и адипиновой кислоты (b)

Fig. 1. Molecular structures of betulin (a) and adipic acid (b) 
позволяет относить LAG-метод к экологически безопасным и рассматривать его как один из методов зеленой химии.

В наших предыдущих работах $[13,14]$ путем кристаллизации из различных растворителей, а именно ацетона, метанола, этанола, пропанола, бутанола, этилацетата, хлороформа и дихлорметана, были получены сольваты бетулина. Не так давно другие авторы получили еще несколько сольватов бетулина [15-17]. Были определены кристаллические структуры сольватов бетулина с этанолом [14], ДМСО [15], метанолом, пропанолом-1, изопропанолом [16], пиридином, бутанолом-2, диметилформамидом, диметилацетамидом [17]. Вследствие ярко выраженной способности бетулина к образованию сольватов метод классической кристаллизации из раствора для получения его смешанных кристаллов кажется малопригодным.

Используя метод механической обработки, при добавлении небольших количеств 1,4-диоксана мы получили смешанный кристалл бетулина с адипиновой кислотой, характеризующийся улучшенной растворимостью по сравнению с исходным бетулином [18]. Целью данной работы стало выяснение особенностей синтеза смешанных кристаллов бетулина с адипиновой кислотой при совместной механической активации с добавлением органических растворителей. Для сравнения с механохимическим методом была изучена кристаллизация смесей бетулина с адипиновой кислотой в тех же растворителях.

\section{Экспериментальная часть}

\section{Материальь}

Бетулин (БЕ) был выделен из бересты по разработанной методике [19] в Институте химии и химической технологии СО РАН (Красноярск, Россия). Его очищали перекристаллизацией из этанола с последующей сушкой на воздухе. Полученный таким образом продукт представлял собой полугидрат бетулина [20]. Согласно данным ВЭЖХ, содержание лупеола в конечном продукте не превышало 1,5-2,5 мас. \%.

Адипиновую кислоту (AA) (Riedel-de Haen AG, Швейцария) использовали без предварительной очистки и сушки. Этилацетат и хлороформ (Reachim, OAO, Россия) очищали перегонкой. Остальные растворители (табл. 1) (Reachim JSC, Россия или Sigma-Aldrich, США) были аналитического качества и использовались без дополнительной очистки.

\section{Приготовление смешанных кристаллов}

\section{механохимическими методами}

Для приготовления смешанных кристаллов около 100 мг смеси бетулин - адипиновая кислота с молярным соотношением 1:1, 1:2 и 2:1 тщательно растирали вручную в агатовой ступке в течение 20 мин. В дополнение к измельчению в сухом состоянии после растирания смеси в течение 5 мин всухую к смеси добавляли 100 мкл растворителя, получившуюся пасту продолжали растирать еще 15 мин.

Смеси бетулина с адипиновой кислотой в тех же соотношениях подвергали обработке также в вибрационной микромельнице и мельнице SPEX 8000 (CertiPrep Inc., США). Условия обработки в вибрационной микромельнице: амплитуда 5 мм, частота 50 Гц, объем барабана 6 мл, диаметр шара 15 мм, масса шара 14 г, масса образца 100 мг. Время обработки составляло 30 мин с добавлением 10 мкл растворителя после 5 мин обработки. При обработке в мельнице 
SPEX 8000 использовали стальной барабан емкостью 60 мл и стальные шары диаметром 6 мм. Соотношение массы образца к массе шаров составляло 1:40, ускорение шаров - 8-10 g. В дополнение к сухому помолу проводили помол с добавлением жидкости: сначала смеси размалывали в сухом виде в течение 5 мин, затем добавляли 1 мл растворителя, пасту измельчали еще в течение 10 мин. Для сравнения обработку проводили в планетарно-центробежной мельнице АГО-2 (ИХТТМ СО РАН) в следующих условиях: стальные барабаны объемом 40 мл, диаметр шаров 6 мм, отношение массы навески к массе шаровой загрузки 1:30, нагрузка на шар $20 \mathrm{~g}$. Время обработки 15 мин.

Кристаллизаџия бетулина и его смесей

с адипиновой кислотой из растворов

Для совместной кристаллизации из растворов в качестве растворителей использовали этанол, пропанол-2 и 1,4-диоксан. Приблизительно 100 мг смеси бетулина с адипиновой кислотой (молярное соотношение 1:1) добавляли к 30 мл растворителя, растворы перемешивали при нагревании (70-80 $\left.{ }^{\circ} \mathrm{C}\right)$. Отфильтрованные растворы оставляли стоять в течение 7 дней при комнатной температуре для кристаллизации при частичном испарении растворителя.

Для сравнения со смешанными кристаллами были синтезированы сольваты бетулина путем кристаллизации из растворов в соответствии с ранее описанными способами [13]. Около 100 мг бетулина добавляли к 50 мл растворителя. Полученную суспензию перемешивали в течение 1 ч при температуре $70-80{ }^{\circ} \mathrm{C}$, осадок отфильтровывали. Фильтрат оставляли для кристаллизации примерно на две недели при комнатной температуре, чтобы получить кристаллы сольватов.

\section{Методы исследования образцов}

Порошковый рентгенофазовый анализ проводили на дифрактометре D8 Advance (Bruker, Германия) с одномерным детектором Lynx-Eye, CuKa-излучение, $2 \Theta=5-70$.

ИК-спектроскопические исследования проводили методом нарушенного полного внутреннего отражения (НПВО) без специальной подготовки образца с использованием Фурье-спектрометра Digilab Excalibur 3100 (Varian, США) и приставки однократного отражения Miracle ATR с кристаллом ZnSe (Pike Technologies, США).

\section{Результаты и обсуждение}

\section{Получение смешанных кристаллов механохимическими методами}

На рис. 2 представлены дифрактограммы исходного бетулина, адипиновой кислоты и их смесей, измельченных в ступке и мельнице SPEX как в сухом виде, так и с добавлением этанола. Видно, что механическая обработка бетулина и адипиновой кислоты по отдельности в присутствии этанола не приводит к изменениям на дифрактограммах. В частности, это говорит о том, что сольват бетулина не образуется при механической обработке бетулина с этанолом. Смеси, обработанные в ступке с добавлением этанола и в сухом виде в мельнице SPEX, не содержат новых рефлексов на дифрактограммах. При сухой обработке в мельнице (рис. 2, кривая 5) наблюдается уширение рефлексов бетулина и адипиновой кислоты, связанное, повидимому, с разупорядочением структуры.

$$
-515-
$$




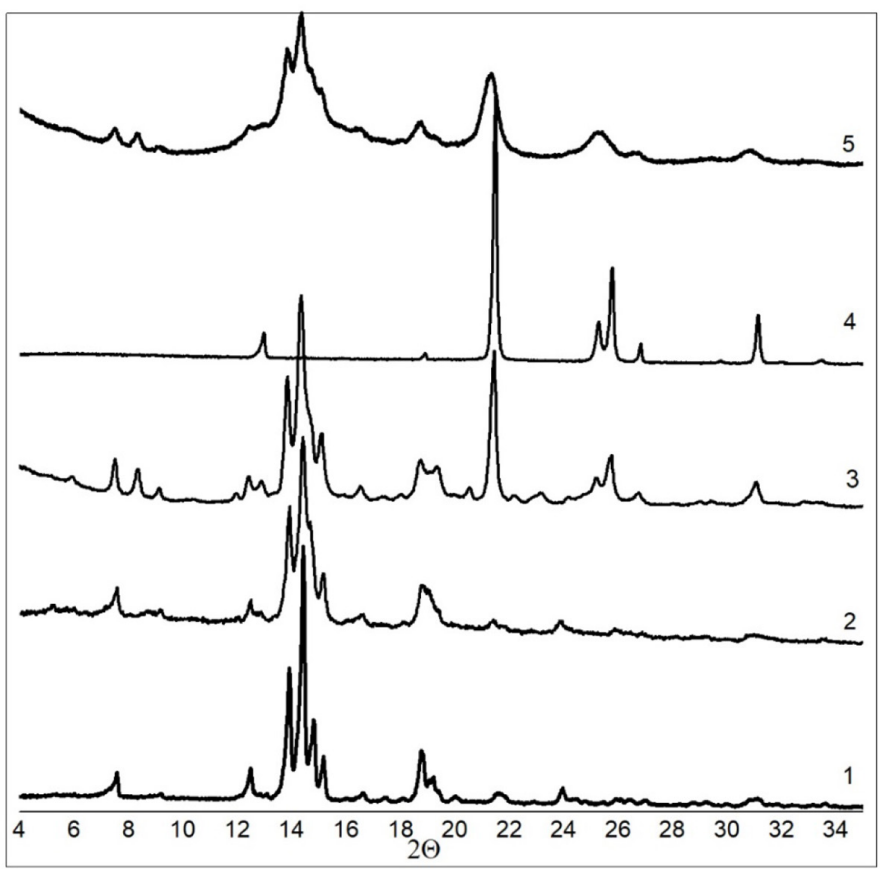

Рис. 2. Дифрактограммы исходного бетулина (1), бетулина, обработанного в мельнице SPEX с добавлением этанола (2), смеси бетулина с адипиновой кислотой, обработанной в ступке с добавлением этанола (3), адипиновой кислоты, обработанной в SPEX с добавлением этанола (4), смеси бетулина с адипиновой кислотой, обработанной в SPEX без растворителя (5)

Fig. 2. RXRD patterns of initial betulin (1), betulin ground in the SPEX mill with addition of ethanol (2); betulin adipic acid mixture ground in the mortar with ethanol (3); adipic acid ground in the SPEX mill with addition of ethanol (4); betulin - adipic acid mixture ground in the SPEX mill without any liquid (5)

Однако при добавлении небольших количеств этанола при обработке смеси в вибрационной мельнице, в мельнице SPEX, как и в мельнице АГО-2, рефлексы исходных реагентов исчезают и появляются новые рефлексы (рис. 3), что позволяет предположить образование смешанного кристалла ВЕ-АА. На рис. 3 приведены дифрактограммы смесей бетулин - адипиновая кислота с различным соотношением компонентов, обработанных в мельницах SPEX и АГО-2 с добавлением этанола. Для соотношений бетулин - адипиновая кислота 1:2 и 2:1 на дифрактограммах кроме рефлексов продукта присутствуют рефлексы адипиновой кислоты или бетулина соответственно. Таким образом, соотношение 1:1 является наиболее подходящим для получения смешанного кристалла и соответствует, по-видимому, стехиометрии смешанного кристалла.

Изменения в ИК-спектрах механически обработанных смесей подтверждают образование смешанного кристалла. На рис. 4 видно, что после механической обработки наблюдается заметный сдвиг валентных колебаний О-Н бетулина (3600-3300 см-1) и адипиновой кислоты (около $2950 \mathrm{~cm}^{-1}$ ). То же наблюдается для валентных колебаний С-О бетулина (около $1020 \mathrm{~cm}^{-1}$ ) и деформационных колебаний О-Н около $1400 \mathrm{~cm}^{-1}$. Это говорит о том, что гидроксильные группы бетулина участвуют в образовании межмолекулярных водородных связей с карбоксильными группами адипиновой кислоты. 


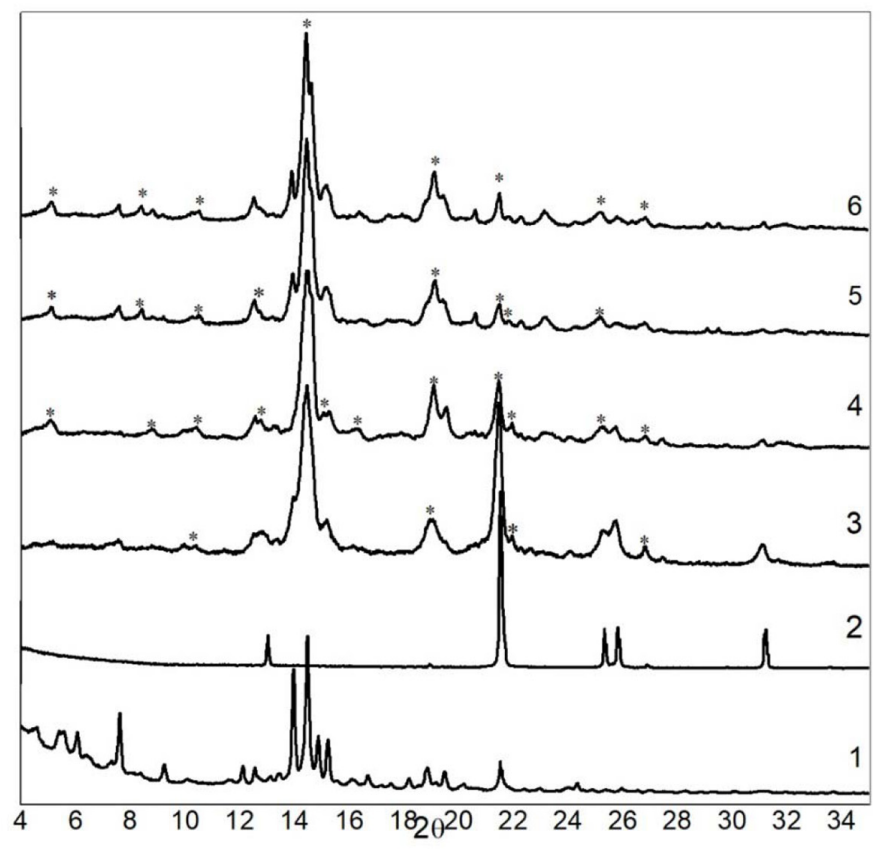

Рис. 3. Дифрактограммы исходного бетулина (1), адипиновой кислоты (2) и смесей бетулин - адипиновая кислота с соотношением компонентов 1:2 (3), 1:1 (4) и 2:1 (5), обработанных в мельнице SPEX с добавлением этанола, и смеси 2:1, обработанной в мельнице АГО-2 с добавлением этанола (6). Новые рефлексы отмечены звездочкой

Fig. 3. PXRD patterns of initial betulin (1), adipic acid (2) and their mixtures in the relation of 1:2 (3), 1:1 (4), and 2:1 (5) ground in the SPEX mill with addition of ethanol; 2:1 betulin - adipic acid mixture treated in AGO-2 mill with addition of ethanol
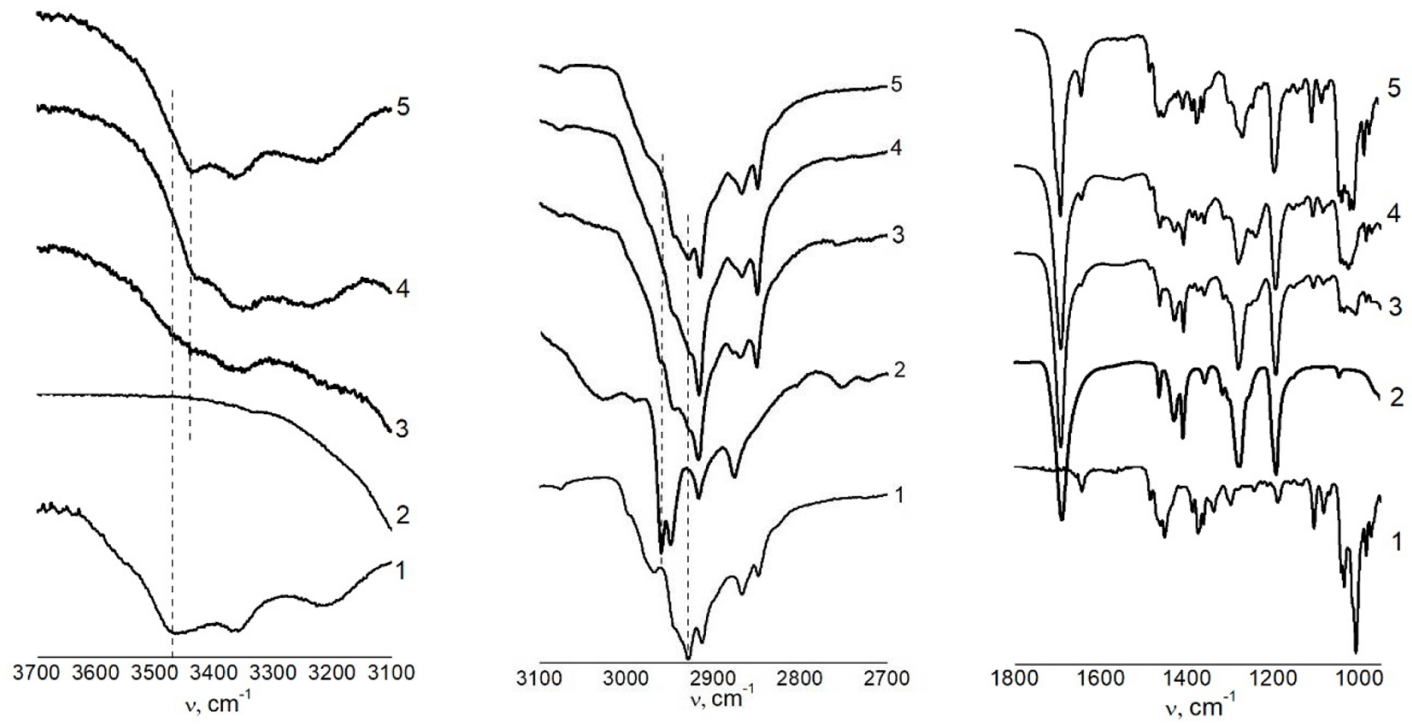

Рис. 4. ИК-спектры исходного бетулина (1), адипиновой кислоты (2); смесей бетулин - адипиновая кислота в молярном соотношении 1:2 (3), 1:1 (4), 2:1 (5), обработанных в мельнице SPEX с добавлением этанола

Fig. 4. IR spectra of initial betulin (1), adipic acid (2) and their mixtures in the relation of 1:2 (3), 1:1 (4), and 2:1 (5) ground in the SPEX mill with addition of ethanol 
Известно, что эффективность механической обработки смесей твердых веществ зависит от механических (мягкость, твердость, хрупкость, пластичность) и химических (кислотность, основность, наличие функциональных групп) свойств компонентов. Высокоэнергонапряженная планетарная мельница АГО-2 бывает часто эффективна для аморфизации лекарственных веществ, так как при механических воздействиях может происходить локальное контактное плавление лекарственного вещества с последующим затвердеванием расплава. С другой стороны, мельница SPEX 8000, по-видимому, более предпочтительна для взаимодействия компонентов, благодаря сдвиговым напряжениям, реализуемым на контактах частиц, и лучшему перемешиванию компонентов. Поэтому дальнейшие эксперименты проводили в мельнице SPEX как наиболее подходящей для проведения механохимического синтеза.

Чтобы исследовать влияние жидкости на образование смешанного кристалла, кроме этанола были использованы также другие растворители: диоксан, изопропанол, этилацетат, хлороформ и четыреххлористый углерод. Добавление диоксана и изопропанола в смеси, измельченные в ступке (данные не показаны) или в мельнице SPEX, привело к изменениям на дифрактограммах (рис. 5) и в ИК-спектрах (рис. 6), которые были аналогичны наблюдаемым при добавлении этанола. На основании этого можно предположить образование одного и того же смешанного кристалла в присутствии этих жидкостей. Напротив, добавление этилацетата,

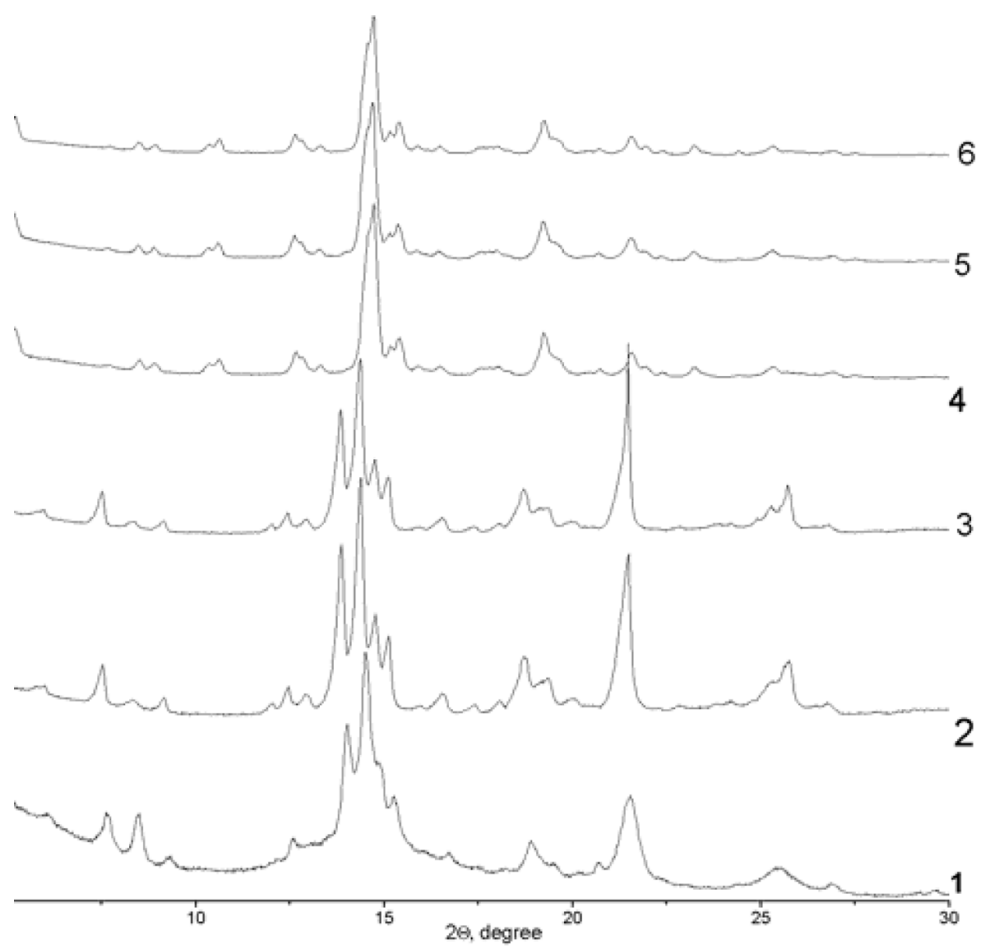

Рис. 5. Дифрактограммы смесей бетулин - адипиновая кислота 1:1, обработанных в мельнице SPEX с добавлением четыреххлористого углерода (1), хлороформа (2), этилацетата (3), изопропанола (4), этанола (5) и диоксана (6)

Fig. 5. PXRD patterns of 1:1 betulin - adipic acid mixtures ground in the SPEX mill with addition of carbon tetrachloride (1), chloroform (2), ethyl acetate (3), isopropanol (4), ethanol (5), and dioxane (6) 


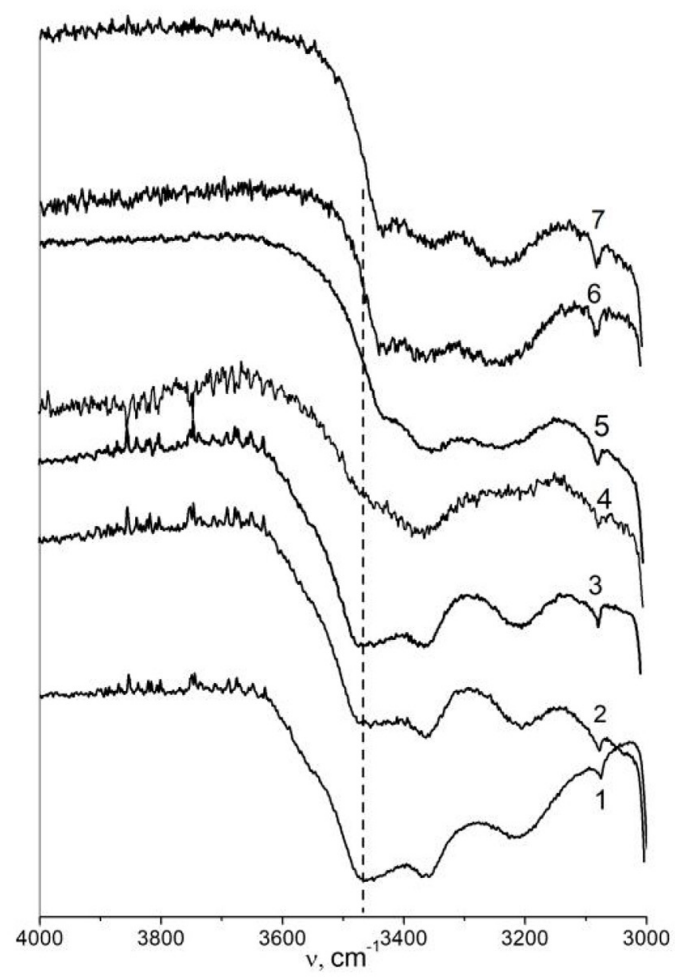

Рис. 6. ИК-спектры бетулина (1) и смесей бетулин - адипиновая кислота 1:1, обработанных в мельнице SPEX с добавлением хлороформа (2), этилацетата (3), четыреххлористого углерода (4), этанола (5), изопропанола (6), диоксана (7)

Fig. 6. IR spectra of betulin (1) and 1:1 betulin - adipic acid mixtures ground in the SPEX mill with addition of chloroform (2), ethyl acetate (3), carbon tetrachloride (4), ethanol (5), isopropanol (6), dioxane (7)

хлороформа и четыреххлористого углерода не привело к каким-либо значительным изменениям на дифрактограммах и в ИК-спектрах по сравнению с исходным бетулином.

Хорошо известно, что свойства растворителей, используемых при механохимической обработке, важны для образования смешанных кристаллов [11, 12, 21]. В частности, в случае растворителей, в которых ни один из компонентов не растворим, смешанные кристаллы не могли быть получены при механической обработке [22]. В табл. 1 приведены некоторые физико-химические свойства растворителей, использованных для синтеза смешанного кристалла бетулина с адипиновой кислотой, а также результаты синтеза. Видно, что нет прямой корреляции между диэлектрическими постоянными растворителей и результатами синтеза смешанного кристалла. Тем не менее оказалось, что смешанные кристаллы были получены с использованием смешивающихся с водой растворителей, в которых адипиновая кислота имеет большую растворимость.

Возможным механизмом, объясняющим влияние растворителя на протекание механохимического синтеза, может быть облегчение диффузионных процессов при протекании синтеза с участием жидкой фазы [21]. Можно предположить, что при добавлении растворителя происходит частичное растворение в нем адипиновой кислоты и смачивание этим раствором поверхности частиц бетулина. При механическом ударе по такой тройной системе увеличива- 
Таблица 1. Физико-химические свойства растворителей, использованных для механохимического синтеза смешанных кристаллов бетулина с адипиновой кислотой, и результат синтеза («+» означает, что смешанный кристалл был получен)

Table 1. The physical-chemical properties of solvents used for mechanochemical synthesis of betulin - adipic acid cocrystals and the result of the synthesis ("+" denotes that the cocrystal was obtained).

\begin{tabular}{|c|c|c|c|c|c|}
\hline Растворитель & $\begin{array}{c}\text { Диэлектрическая } \\
\text { постоянная [24] }\end{array}$ & $\begin{array}{c}\text { Смешиваемость } \\
\text { с водой, масс. \% } \\
{[25],}\end{array}$ & $\begin{array}{c}\text { Растворимость } \\
\text { адипиновой } \\
\text { кислоты }[26,27], \\
10^{4} x_{\mathrm{i}}{ }^{*}\end{array}$ & $\begin{array}{c}\text { Растворимость } \\
\text { бетулина [28], } \\
10^{4} x_{\mathrm{i}}^{*}\end{array}$ & $\begin{array}{l}\text { Результат } \\
\text { синтеза** }^{*}\end{array}$ \\
\hline Этанол & 24,3 & смешивается & 326 & 8,98 & + \\
\hline Изопропанол & 18,3 & смешивается & 287 & 14.63 & + \\
\hline Этилацетат & 6,02 & 9,7 & не найдено & 20.66 & - \\
\hline Хлороформ & 4,7 & 0,065 & 20,95 & 43.70 & - \\
\hline $\begin{array}{l}\text { Четыреххлористый } \\
\text { углерод }\end{array}$ & 2,23 & 0,01 & не найдено & не найдено & - \\
\hline 1,4-Диоксан & 2,21 & смешивается & 347 & не найдено & + \\
\hline
\end{tabular}

${ }^{*} x_{\mathrm{i}}-$ растворимость, мольные доли

** + смешанный кристалл получен.

ется температура и реализуются сдвиговые пластические деформации, что может приводить к окклюдированию раствора внутрь компактной смеси. В результате механического сжатия температура раствора может превысить температуру кипения жидкостей. Известно, что такой гидротермальный режим реализуется при обработке минеральных веществ в водных средах [23]. При таких условиях можно ожидать повышения концентрации растворенного бетулина в применяемых растворителях. Механическое воздействие может вызывать разупорядочение поверхностных слоев бетулина, что способствует ускорению процесса растворения и последующего образования смешанных кристаллов бетулина с адипиновой кислотой.

\section{Приготовление смешанных кристаллов}

методами кристаллизации из раствора

Для сравнения с механохимическим синтезом кристаллизацию из раствора проводили с использованием тех же растворителей, что и для механической обработки: диоксана, этанола и изопропанола. Как показали эксперименты по кристаллизации, из раствора смеси бетулин адипиновая кислота в этаноле кристаллизуется сольват бетулина с этанолом (рис. 7). Можно предположить, что образование этого сольвата термодинамически более выгодно, чем образование смешанного кристалла. Тем не менее в случае раствора в изопропаноле кристаллизуется смесь сольвата и смешанного кристалла. Более того, из раствора в диоксане был получен смешанный кристалл ВЕ-АА, идентичный полученному механохимическим методом.

Очевидно, что при равновесной кристаллизации необходимым условием образования смешанных кристаллов является более низкая растворимость смешанного кристалла в используемом растворителе по сравнению с растворимостью отдельных компонентов или других образующихся продуктов. По этой причине кристаллизация различных продуктов - сольвата или смешанного кристалла - может происходить при кристаллизации из определенного рас-

$$
-520-
$$




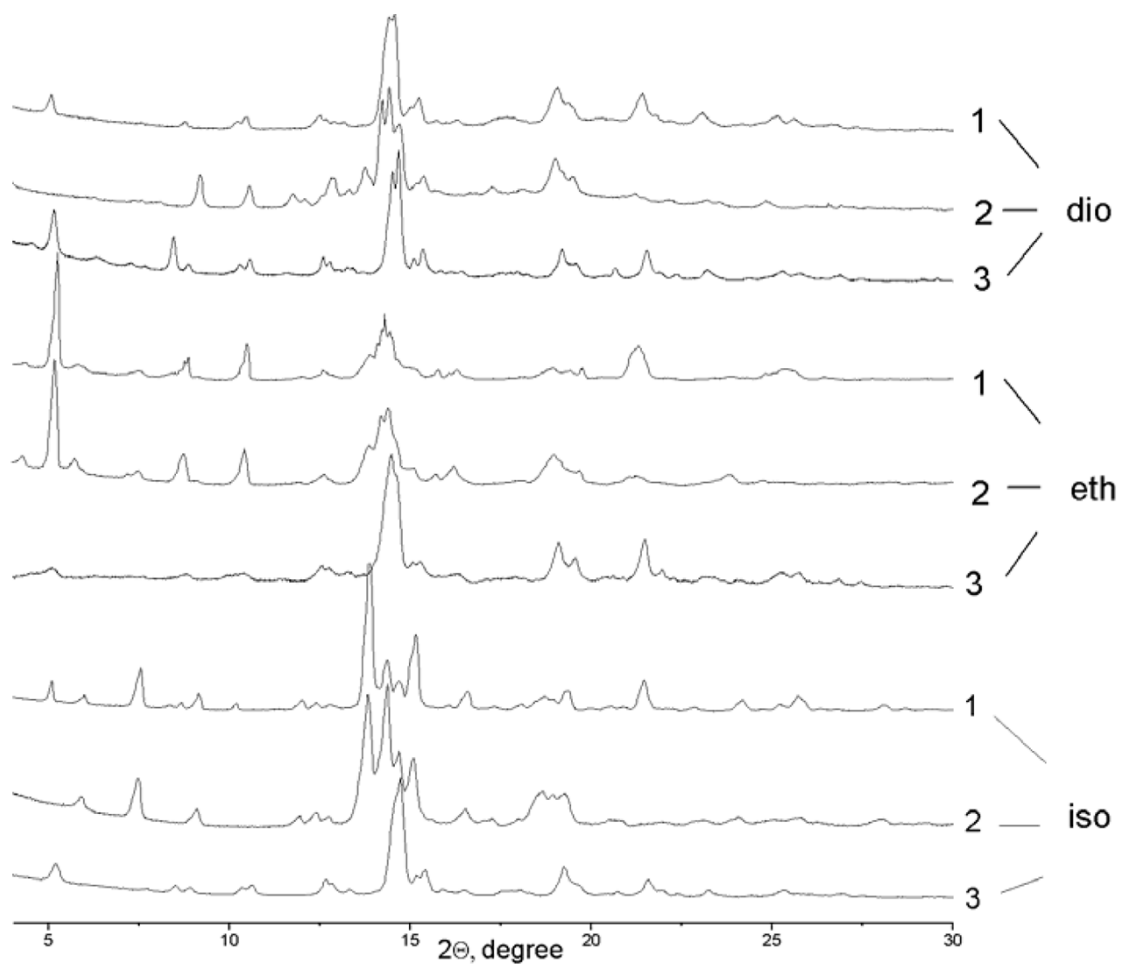

Рис. 7. Дифрактограммы продуктов, полученных при кристаллизации смесей бетулин - адипиновая кислота из раствора (1); сольватов бетулина с соответствующим растворителем (2); смешанного кристалла бетулина с адипиновой кислотой, полученного механохимическим методом с использованием того же растворителя (3). Обозначения: iso = изопропанол, eth = этанол, dio = диоксан

Fig. 7. PXRD patterns of products obtained by crystallization of betulin - adipic acid mixtures from solution (1); betulin solvates with an appropriate solvent (2); cocrystal of betulin with adipic acid obtained by LAG method using the same solvent (3). Notation: iso = isopropanol, eth $=$ ethanol, dio $=$ dioxane

творителя. С другой стороны, механохимический синтез часто дает продукты, соответствующие быстрой кристаллизации [22], что и приводит к образованию смешанных кристаллов бетулина с адипиновой кислотой при механической обработке.

\section{Заключение}

Установлено, что бетулин может образовывать смешанные кристаллы с адипиновой кислотой при механохимической обработке с добавлением небольших количеств органического растворителя. Условием образования смешанного кристалла является использование органических растворителей, способных эффективно растворять адипиновую кислоту. Показано, что механическая обработка с добавлением небольших количеств органического растворителя более предпочтительный метод получения смешанных кристаллов по сравнению с кристаллизацией из раствора вследствие высокой склонности бетулина к образованию сольватов. 


\section{Благодарности / Acknowledgements}

Работа выполнена в рамках государственных заданий ИХТТМ СО РАН (проект АААА-А17-117030310274-5) и ИХХТ СО РАН (проект АААА-А17-117021310218-7). Авторы благодарят Е.А. Лосева за регистрацию ИК-спектров.

This work was conducted within the framework of the budget projects AAAA-A17-117030310274-5 for ISSCM SB RAS and AAAA-A17-117021310218-7 for ICCT SB RAS. The authors are grateful to E. Losev for IR spectra registration.

\section{Список литературы / References}

1. Alakurtti S., Mäkelä T., Koskimies S., Yli-Kauhaluoma J. Pharmacological properties of the ubiquitous natural product betulin. European Journal of Pharmaceutical Sciences 2006. Vol. 29, P. 1-13.

2. Król S.K., Kiełbus M., Rivero-Müller A., Stepulak A. Comprehensive review on betulin as a potent anticancer agent. BioMed Research International 2015. Vol. 2015, P. 1-11.

3. Кузнецова С.А., Шахтшнейдер Т.П., Михайленко М.А., Маляр Ю.Н., Замай А.С., Болдырев В.В. Получение механокомпозитов диацетата бетулина с арабиногалактаном и изучение их противоопухолевых свойств. Журнал Сибирского федерального университета. Химия 2013. T. 6(2), C. 192-202. [Kuznetsova S.A., Shakhtshneider T.P., Mikhailenko M.A., Malyar Yu.N., Zamay A.S., Boldyrev V.V. Preparation of mechanocomposites of betulin diacetate with arabinogalactan and study their anti-cancer properties. Journal of Siberian Federal University. Chemistry 2013. Vol. 6(2), P. 192-202 (In Russ.)]

4. Патент 02437649 РФ. Котова Т.В., Рыбальченко О.В., Михайлова О.Г., Каратушина Л.Н., Потокин И.Л., Добрица В.П. Способ получения сухих липосомальных препаратов (варианты). Опубл. 10.05.2011 [Patent 02437649 RU. Kotova T.V., Rybalchenko O.V., Mikhailova O.G., Karatushina L.N., Potokin I.L., Dobritsa V.P. Method for obtaining dry liposomal preparations (Variants). Publ. Date 10.05.2011 (In Russ.)].

5. Wang H.M., Soica C.M., Wenz G. A comparison investigation on the solubilization of betulin and betulinic acid in cyclodextrin derivatives. Natural Product Communications 2012. Vol. 7, P. 289-291.

6. Pozharitskaya O.N., Karlina M.V., Shikov A.N., Kosman V.M., Makarov V.G., Casals E., Rosenholm J.M. Pharmacokinetics and tissue disposition of nanosystem-entrapped betulin after endotracheal administration to rats. European Journal of Drug Metabolism and Pharmacokinetics 2017. Vol. 42, P. 327-332.

7. Healy A.M., Worku Z.A., Kumar D., Madi A.M. Pharmaceutical solvates, hydrates and amorphous forms: A special emphasis on cocrystals. Advanced Drug Delivery Reviews 2017. Vol. 117, P. 25-46.

8. Jones W., Motherwell W.D.S., Trask A.V. Pharmaceutical cocrystals: An emerging approach to physical property enhancement. MRS Bulletin 2006. Vol. 31, P. 875-879.

9. Qiao N., Li M., Schlindwein W., Malek N., Davies A., Trappitt G. Pharmaceutical cocrystals: An overview. International Journal of Pharmaceutics 2011. Vol. 419, P. 1-11.

10. Rodrigues M., Baptista B., Lopes J.A., Sarraguça M.C. Pharmaceutical cocrystallization techniques. Advances and challenges. International Journal of Pharmaceutics 2018. Vol. 547, P. 404-420. 
11. Braga D., Maini L., Grepioni F. Mechanochemical preparation of co-crystals. Chemical Society Reviews 2013. Vol. 42, P. 638-764.

12. Hasa D., Jones W. Screening for new pharmaceutical solid forms using mechanochemistry: A practical guide. Advanced Drug Delivery Reviews 2017. Vol. 117, P. 147-161.

13. Михайленко М.А., Шахтшнейдер Т.П., Брезгунова М.Е., Дребущак В.А., Кузнецова С.А., Болдырев В.В. Получение и исследование физико-химических свойств сольватов бетулина. Химия растительного сырья 2010. № 2, С. 63-70. [Mikhailenko M.A., Shakhtshneider T.P., Brezgunova M.E., Drebushchak V.A., Kuznetsova S.A., Boldyrev V.V. Obtaining and studying the physical and chemical properties of betulin solvates. Khimija Rastitel'nogo Syr' ja 2010. Iss. 2, P. 6370. (In Russ.)].

14. Drebushchak T.N., Mikhailenko M.A., Brezgunova M.E., Shakhtshneider T.P., Kuznetsova S.A. Crystal structure of betulin ethanol solvate. Journal of Structural Chemistry 2010. Vol. 51, P. 798-801.

15. Boryczka S., Michalik E., Jastrzebska M., Kusz J., Zubko M., Bebenek E. X-ray crystal structure of betulin-DMSO solvate. Journal of Chemical Crystallography 2012. Vol. 42, P. 345-351.

16. Yang D., Gong N., Zhang L., Lu Y. Isostructurality among 5 solvatomorphs of betulin: X-Ray structure and characterization. Journal of Pharmaceutical Sciences 2016. Vol. 105, P. 1867-1873.

17. Yang D., Gong N., Zhang L., Lu Y., Du G. Structural and computational study of four new solvatomorphs of betulin: A combined X-ray, Hirshfeld surface, and thermal analysis. Journal of Pharmaceutical Sciences 2017. Vol. 106, P. 826-834.

18. Myz S.A., Mikhailovskaya A.V., Mikhailenko M.A., Bulina N.V., Kuznetsova S.A., Shakhtshneider T.P. New crystalline betulin-based materials: improving betulin solubility via cocrystal formation. Materials Today: Proceedings 2019. Vol. 12, P. 82-85.

19. Патент 2264411 РФ. Кузнецова С.А., Кузнецов Б.Н., Михайлов А.Г., Левданский В.А. Способ получения бетулина. Опубл. 20.11.2005. [Patent 2264411 RU. Kuznetsova S.A., Kuznetsov B.N., Mikhailov A.G., Levdanskii V.A. Method of production of betulin. Publ. Date 20.11.2005 (In Russ.)].

20. Дребущак Т.Н., Михайловская А.В., Дребущак В.А., Михайленко М.А., Мызь С.А., Шахтшнейдер Т.П., Кузнецова С.А. Кристаллические формы бетулина. Полиморфизм или псевдополиморфизм? Журнал структурной химии. 2020. № 8, С. 13281334. [Drebushchak T.N., Mikhailovskaya A.V., Drebushchak V.A., Mikhailenko M.A., Myz S.A., Shakhtshneider T.P., Kuznetsova S.A. Crystal forms of betulin. Polymorphism or pseudopolymorphism? Journal of Structural Chemistry 2020. No. 8, P. 1260-1266. (In Russ.)].

21. Friščić T., Jones W. Recent advances in understanding the mechanism of cocrystal formation via grinding. Crystal Growth and Design 2009. Vol. 9, P. 1621-1637.

22. Myz S.A., Shakhtshneider T.P., Tumanov N.A., Boldyreva E.V. Preparation and studies of the co-crystals of meloxicam with carboxylic acids. Russian Chemical Bulletin 2012. Vol. 61, P. 1798-1809.

23. Boldyrev V.V. Hydrothermal reactions under mechanochemical action. Powder Technology 2002. Vol. 122(2-3), P. 247-254.

24. Gordon A.J., Ford R.A. The Chemist's Companion. New York: A Wiley-Intersci. Publ., 1972.

25. Kirk-Othmer. Encyclopedia of Chemical Technology. New York: John Wiley \& Sons, Inc., 1994.

26. Gaivoronskii A.N., Granzhan V.A. Solubility of adipic acid in organic solvents and water. Russian Journal of Applied Chemistry 2005. Vol. 78, P. 404-408. 
27. Wei D., Cao W. Solubility of adipic acid in acetone, chloroform, and toluene. Journal of Chemical and Engineering Data 2009. Vol. 54, P. 152-153.

28. Cao D., Zhao G., Yan W. Solubilities of betulin in fourteen organic solvents at different temperatures, Journal of Chemical and Engineering Data 2007. Vol. 52, P. 1366-1368. 